\title{
SOME BULGARIAN PRE-ENLARGEMENT RESEARCH TRENDS
}

\author{
Dan S. Radut \\ Alicante University, Department of Public Health
}

\begin{abstract}
SUMMARY
Aim. Bulgaria joined the European Union in 2007. This study aims to analyse Bulgarian scientific health output over a five year period before enlargement, highlighting both its interests and concordance with European health recommendations.

Methods. A bibliometric analysis was undertaken in MEDLINE between 2000 and 2004 according to a year-by-year bibliographic search. The articles were classified by fourteen fields according to the main European Union health report recommendations.

Results. 2,176 articles were found, distributed as follows: $15.63 \%$ in $2000,20.50 \%$ in $2001,20.63 \%$ in $2002,19.9 \%$ in 2003 and $23.25 \%$ in 2004. $89.48 \%$ of the articles were written in English, $78.81 \%$ of the total scientific output was published abroad. Most of the articles were signed by Bulgarian authors and were carried out in Bulgarian research centers.

Conclusion. Increased number of articles was noted mainly in the basic research field and global clinical medicine. Bulgarian research priorities generally were aligned with the European Union health recommendations. More sources are recommended to be consulted and more analysis conducted of the Bulgarian research.
\end{abstract}

Key words: bibliometrics, health, research, scientific output, Bulgaria, European Union

Address for correspondence: D. S. Radut, Alicante University, Department of Public Health, Crta. San Vicente del Raspeig s/n, 03690, San Vicente del Raspeig, Alicante, Spain. E-mail: radut@ua.es

\section{INTRODUCTION}

Significant interest in scientific research has been observed in recent decades in Europe, including health research (1). Several European countries increased their scientific output (SO) year by year and sometimes the scientists show their support for research through public demonstration (2-5). European union support for research has been demonstrated by financial investment, such as the 73 billion euro fund, of which 8.37 billions of euro were alloted for health research (6). The European Parliament (EP) has also proposed greater solidarity and increased international co-operation between countries in health issues (7). This could have a positive effect on research, since one of the factors which must be taken into account when discussing medical research in Europe are countries' levels of SO, particularly when considering the specific characteristics of specific Member States. Since scientific research in Europe places great importance on the field of health and the European Union (EU) moved its boundaries to East, Eastern Europe is an ideal area in which to study this sector. The Balkan region requires greater attention, taking into account the lack of reforms, documented dysfunction in the field of health and the decrease in life expectancy after the 1990s in comparison with the 'old' Member States $(8,9)$. Bulgaria, where until recently the financial resources in the medical field used to be provided totally from central public funds under a national insurance scheme (10), is a country which economy changed post-1989, following the change of political regime. In spite of some difficulties experienced while seeking to meet the conditions for entry set by the European Council, which was closely monitoring the country's progress, in 2007 Bulgaria became a new Member State of the EU (11). This did not exempt Bulgaria from continuing in its efforts to solve its health problems, such as modest conditions in mental health institutions or child welfare provisions (12), the declining Bulgarian population, infant and total mortality figures, tuberculosis, and ischaemic heart disease and stroke (13). The principal post-1997 health reform law was the Bulgarian Health Act 2004 (14).

The bibliometric analysis may allow the study of SO and/or its evolution, in national or international context, in specific or general field in accordance with specific period of time. The aim of this work was to study Bulgarian scientific health output retrieved from the database MEDLINE (accessed through PubMed) and to analyze its characteristics over a five year period, documenting both its tendency and its agreement with the EP's health strategy by means of a bibliographic review.

\section{MATERIAL AND METHODS}

A bibliographical search of scientific articles about Bulgaria between 2000 and 2004 was carried out in MEDLINE (accessed through PubMed) as world's largest medical library (15), leading online database of biomedical literature records and essential tool used by scientists and physicians to monitor research developments (16). The search was carried out by year by using a basic search equation (BSE): 'Bulgaria'. All abstracts of the articles added to MEDLINE between 2000 and 2004 were reviewed. Inclusion and exclusion criteria: Articles on Bulgaria in any field of research, 
Table 1. EU Parliament main health objectives as per the 23 September, 2002 report targeting the period 2003-2008

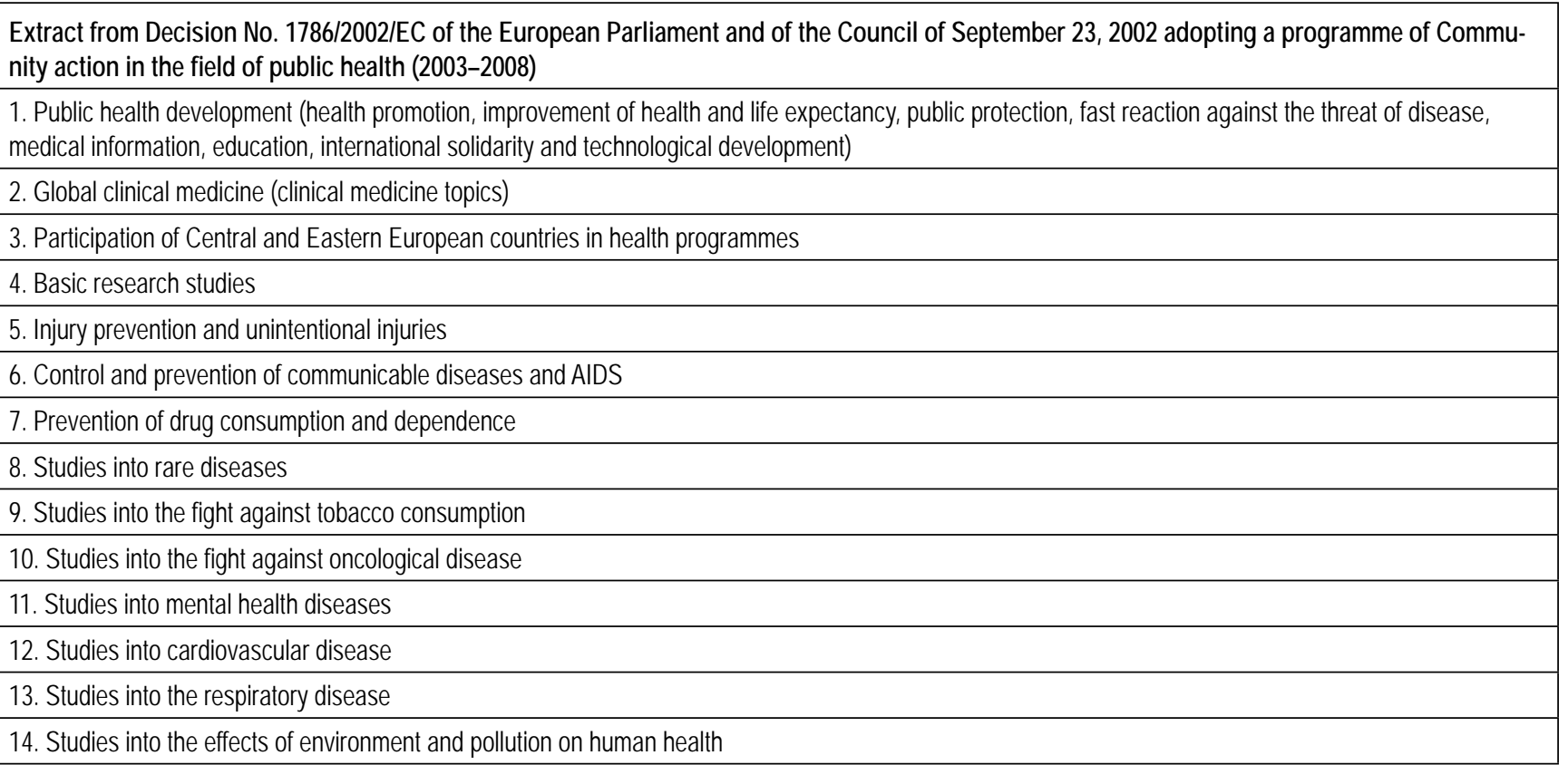

written by any author, carried out by any national/international research center and added to MEDLINE between 2000 and 2004 were included. Articles excluded were those which only listed the country along with others, or mentioned it only in insignificant examples (rather than specifically carrying out research on Bulgaria) and articles written by foreign authors in foreign research centers and simply published in Bulgarian journals. By using the search Tag [pl] added to the term 'Bulgaria', a categorization by year according to the journal of publication was done classifying the articles into published in 'national' or 'foreign' journals. By using the language search option permitted by the database, the articles were also classified by year according to the language of publication as 'Bulgarian', 'English' or 'other language'. After the application of the inclusion and exclusion criteria and for information purpose only owing to the difficulty to determine exactly this parameter, a classification by 'Bulgarian', 'foreign', and 'Bulgarian and foreign' authors was carried out to determine Bulgarian authors' SO, foreign authors' output about Bulgaria and collaboration between Bulgarian and foreign researchers. The classification was carried out using by way of guidance the name(s) of the author(s), the language used, the research center and the journal in which it was published. The articles not signed by any author were classified into the 'no author listed' category. The institutions in which the studies were undertaken were also classified by 'national' center, 'foreign' center, bi/multi center (articles revealing more than one center in the affiliation section). When no center was mentioned in the affiliation, the references were classified as 'no center listed'.

A synthesis of the most recent EP health report was carried out and summarised into fourteen objectives as per the $23 \mathrm{Sep}$ tember, 2002 report, (17) targeting the period 2003-2008 (Table 1). To observe points of correspondence between Bulgarian health interests and to relate them to European health objectives, an agreement equation was drawn up, linking the European objective with the corresponding article. In the EP's objective 'Global Clinical Medicine' were included those articles relating pathology or illness in any medical/health branch but not related to the unintentional injuries or injury prevention, or belonging to the field of communicable diseases and AIDS, rare/uncommon diseases, oncology, cardiovascular, respiratory and mental health (psychiatric and/or psychological) diseases, which were classified individually. The 'Basic Research Studies' category included all references referring to studies in the field of basic sciences (e.g. anatomy, physiology, histology, molecular biology, bio/physics, bio/chemistry, genetics, animal/laboratory studies etc.) but not in the field of the topics encompassed by the others EP's objectives. All the articles were classified and the statistical analysis was carried out using the SPSS 14 program. Frequencies and percentages were determined and $95 \%$ confidence intervals $(95 \%$ CI) were calculated. A classification reproducibility measurement was performed by using an agreement analysis obtained from two reviewers, measuring the kappa index. A kappa index of 0.79 (95\% CI: 0.62-0.94) was obtained.

\section{RESULTS}

2,176 articles written mainly in English and Bulgarian were found between 2000 and 2004 according to the BSE, distributed as follows: 340 (15.63\%; 95\% CI: $14.10-17.15)$ in 2000, 446

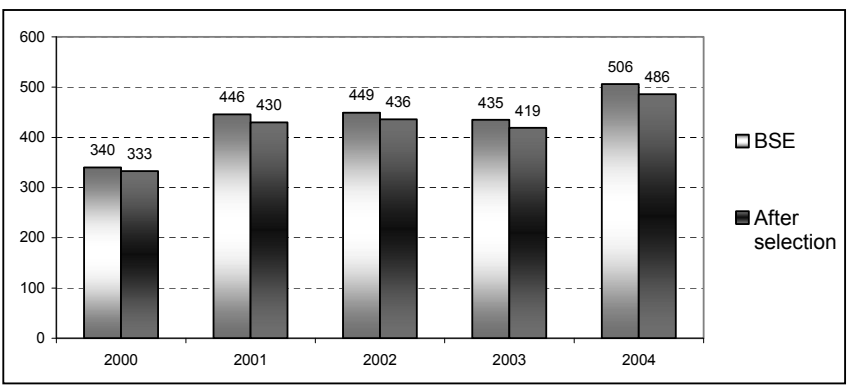

Fig. 1. Scientific output (n) in Bulgaria by year between 2000 and 2004. 
Table 2. Annual distribution of articles by SO, language and journal of publication in numerical (and percentage terms) according to the BSE

\begin{tabular}{|l|c|c|c|c|c|c|c|}
\hline \multicolumn{2}{|l|}{ Year } & $\mathbf{2 0 0 0}$ & $\mathbf{2 0 0 1}$ & $\mathbf{2 0 0 2}$ & $\mathbf{2 0 0 3}$ & $\mathbf{2 0 0 4}$ & Total \\
\hline \multicolumn{2}{|l|}{ Scientific output } & $340(15.63)$ & $446(20.50)$ & $449(20.63)$ & $435(19.99)$ & $506(23.25)$ & $2,176(100)$ \\
\hline \multirow{4}{*}{ Language } & Bulgarian & $20(10.36)$ & $100(51.81)$ & $41(21.24)$ & $10(5.18)$ & $22(11.40)$ & $193(100)$ \\
\cline { 2 - 8 } & English & $315(16.18)$ & $338(17.36)$ & $397(20.39)$ & $420(21.57)$ & $477(24.50)$ & $1,947(100)$ \\
\cline { 2 - 8 } & other & $5(13.89)$ & $8(22.22)$ & $11(30.56)$ & $5(13.89)$ & $7(19.44)$ & $36(100)$ \\
\hline \multirow{2}{*}{ Journal } & Bulgarian & $81(17.57)$ & $142(30.80)$ & $85(18.44)$ & $53(11.50)$ & $100(21.69)$ & $461(100)$ \\
\cline { 2 - 8 } & Foreigner & $259(15.10)$ & $304(17.73)$ & $364(21.22)$ & $382(22.27)$ & $406(23.67)$ & $1,715(100)$ \\
\hline
\end{tabular}

Table 3. Annual distribution of articles by SO, author characteristics and research center in numerical (and percentage terms) after applying the inclusion/exclusion criteria

\begin{tabular}{|c|c|c|c|c|c|c|c|}
\hline \multicolumn{2}{|l|}{ Year } & 2000 & 2001 & 2002 & 2003 & 2004 & Total \\
\hline \multicolumn{2}{|c|}{ Scientific output } & 333 (15.83) & $430(20.44)$ & $436(20.72)$ & 419 (19.91) & $486(23.10)$ & $2,104(100)$ \\
\hline \multirow{4}{*}{ Author } & Bulgarian & $273(16.85)$ & $359(22.16)$ & 318 (19.63) & $320(19.75)$ & $350(21.60)$ & $1,620(100)$ \\
\hline & Foreigner & $12(32.43)$ & $4(10.81)$ & $12(32.43)$ & $3(8.11)$ & $6(16.22)$ & $37(100)$ \\
\hline & $\begin{array}{l}\text { Bulgarian \& } \\
\text { Foreigner }\end{array}$ & $47(10.85)$ & $65(15.01)$ & $99(22.86)$ & 95 (21.94) & $127(29.33)$ & $433(100)$ \\
\hline & No author listed & $1(7.14)$ & $2(14.29)$ & $7(50.0)$ & $1(7.14)$ & $3(21.43)$ & $14(100)$ \\
\hline \multirow{4}{*}{$\begin{array}{l}\text { Research } \\
\text { Center }\end{array}$} & Bulgarian & 286 (15.73) & $380(20.90)$ & $349(19.20)$ & $373(20.52)$ & $430(23.65)$ & $1,818(100)$ \\
\hline & Foreigner & $23(18.40)$ & $18(14.40)$ & $29(23.20)$ & $28(22.40)$ & $27(21.60)$ & $125(100)$ \\
\hline & Bi/multi center & $1(25.0)$ & $1(25.0)$ & $1(25.0)$ & - & $1(25.0)$ & $4(100)$ \\
\hline & No center listed & $23(14.65)$ & $31(19.75)$ & $57(36.31)$ & $18(11.46)$ & $28(17.83)$ & 157 (100) \\
\hline
\end{tabular}

(20.50\%; 95\% CI: $18.80-22.19)$ in 2001, 449 (20.63\%; 95\% CI: $18.93-22.33)$ in 2002, 435 (19.99\%; 95\% CI: 18.31-21.67) in 2003 and 506 (23.25\%; 95\% CI: 21.48-25.03) in 2004 (Fig. 1). 1,947 (89.48\%) articles were written in English, 193 (8.87\%) in Bulgarian and $36(1.65 \%)$ in other language(s). 1,715 (78.81\%) articles were published abroad and $461(21.19 \%)$ in a national environment (Table 2). All the articles retrieved involved the term 'Bulgaria' but after the application of the inclusion/exclusion criteria 2,104 references were selected, distributed as follows: 333 (15.83\% ; 95\% CI: $14.27-17.39)$ in 2000, 430 (20.44\%; 95\% CI: $18.71-22.16)$ in 2001,436 (20.72\%; 95\% CI: 18.99-22.45) in 2002,419 (19.91\%; 95\% CI: $18.21-21.62)$ in 2003 and 486 (23.10\%; 95\% CI: $21.30-24.90)$ in 2004. 1,620 (77\%; 95\% CI: 75.20-78.79) articles were signed by Bulgarian authors, 37 (1.76\%; 95\% CI: 1.20-2.32) by foreign authors, 433 (20.58\%; 95\% CI: 18.85-22.31) were carried out in collaboration between Bulgarian and foreign authors and $14(0.67 \%$; 0.32-1.01) were classified as into the 'no author listed' category. Most of the studies, 1,818 (86.41\%; 95\% CI: 84.94-87.87) were conducted in Bulgarian research centers, 125 (5.94\%; 95\% CI: 4.93-6.95) in foreign centers. The Table 3 shows the annual distribution by $\mathrm{SO}$, author characteristics and research center.

As far as concordance between Bulgarian SO and the EP's recommendations is concerned, this was best achieved in basic research, followed by global clinical medicine and public health topics, while the lowest levels of concordance were seen in tobacco consumption, drug abuse and consumption, injury prevention and unintentional injuries (Table 4).

\section{DISCUSSION AND CONCLUSIONS}

In the current study, approximately steady increase of SO was observed during the years studied (Figure 1). For every year studied, the majority of authors were Bulgarian; their numbers increased during the period studied. Collaboration between Bulgarian and foreign authors improved, almost doubling in 2002 and growing almost threefold in 2004 suggesting rising presence of the Bulgarian scientists in foreign research centres as a result of increased mobility among health care professionals in Europe $(18,19)$, increasing foreign interest in studying Bulgaria, or both. A growing number of Bulgarian research centers was noted, while the number of foreign research centers originating articles remained approximately constant. Likewise, despite a peak production in 2001 of articles published in Bulgarian, the use of this language decreased after this year meanwhile an increase of the articles written in English was observed. The increased use of English as language of publication even in a national context was noted in some other countries as well; Kevelaitis and Grabauskas (20) pointed out in a study carried out between 2001-2006 an increase of English as language of publication in Lithuania.

When related to EU health recommendations for 2003-2008, the basic research field was best covered, followed by global clinical medicine. Satisfactorily, the SO focusing Public Health is the third classified, considering Bulgaria's difficulties in this area as revealed in some studies $(11,21,22,23)$. Given the prior data relating to the past development of and future predictions for HIV/AIDS and sexually transmitted diseases in Eastern Europe 
Table 4. Relationship between research on Bulgaria and EP health objectives

\begin{tabular}{|l|c|c|c|}
\hline EP health objectives & Articles ( $\mathbf{n}$ & $(\%)$ & $95 \% \mathrm{Cl}$ \\
\hline Basic research & 959 & $(45.58)$ & $43.45-47.71$ \\
\hline Global clinical medicine & 416 & $(19.77)$ & $18.07-21.47$ \\
\hline Public health development & 176 & $(8.37)$ & $7.18-9.55$ \\
\hline Communicable disease and HIVIAIDS & 175 & $(8.32)$ & $7.14-9.50$ \\
\hline Oncological disease & 103 & $(4.90)$ & $3.97-5.82$ \\
\hline Environmental and pollution studies & 80 & $(3.80)$ & $2.99-4.62$ \\
\hline Cardiovascular disease & 49 & $(2.33)$ & $1.68-2.97$ \\
\hline Central-Eastern European health programs & 40 & $(1.90)$ & $1.32-2.48$ \\
\hline Mental health & 34 & $(1.62)$ & $1.08-2.15$ \\
\hline Respiratory disease & 26 & $(1.24)$ & $0.76-1.71$ \\
\hline Rare/uncommon disease & 23 & $(1.09)$ & $0.65-1.54$ \\
\hline Injuries prevention, unintentional injuries & 15 & $(1.09)$ & $0.35-1.07$ \\
\hline Drug abuse and consumption & 4 & $(0.19)$ & $0.0-0.38$ \\
\hline Tobacco consumption & 4 & $(0.19)$ & $0.0-0.38$ \\
\hline Total & 2,104 & & \\
\hline
\end{tabular}

and in some specific ethnic groups in Bulgaria $(24,25)$, a good interest on the Bulgarian research in this area was noted. Given the worrying development of oncological disease in Bulgaria that have been observed last years $(26,27)$, local research was found to have paid satisfactory attention to this field. Clinical medicine focuses its interest on the cardiovascular sector as this represents another problem which Bulgaria had to face during its transition period, bearing in mind the high levels of problems such as stroke, which incidence is particularly high in certain regions of Bulgaria (28). Further some research interest on the mental health was also noted. Some data mention that this country has enacted legislation to develop health services rendered to people with mental problems in agreement with the European Commission's requirement for 'increased efforts' to improve environment in mental health institutions (12). Despite of the concerning data on tobacco consumption in Bulgaria and their negative consequences for people's health $(29,30)$, there was a low level of interest in research in this area. Taking into account that the Eastern European countries experienced similar post-1990s transition difficulties it is considered positive and constructive to promote the interest in research and collaboration among Central and Eastern European health programs. Like other former post-socialist countries in the region, Bulgaria had a healthcare system chronically short of funds; its medical sector having been entirely financed by the government (10). The SO of any country may be related to the countries' economic status, the poverty in countries undergoing post-socialist transition being widespread limiting human development (31). The source of funding of the health field is an important aspect; in 2004 the total health budget in Bulgaria represented only $8 \%$ of the Gross Domestic Product (GDP) (32) while the average of the same parameter was 9.2 and 15.4 in the EU 15 countries and USA respectively (33).

There was therefore quite good concordance of the Bulgarian medical research with the EU main health objectives before enlargement time but perhaps increased attention on areas such as the fight against tobacco consumption should have been observed.
Given the fact that the methodology used in this work might leave out data published in journals not visible in the database chosen for this study, more sources are recommended to be consulted and more research to be conducted by using bibliometric studies. Analysis of the Bulgarian SO (post EU enlargement) focusing on research interest and trends, collaboration and/or other parameters are also recommended. Studies using similar methodology have assessed SO in basic sciences such as molecular biology, and total SO over a set period of time in relation to health policies (34, 35). Similar Iberian studies were carried out to assess research in specific medical areas or in fields such as communication and health in both national and international contexts $(36,37)$.

\section{Acknowledgements}

An excellent technical support was facilitated by the University Miguel Hernandez, Campus Sant Joan - my thanks go in particular to Prof. Enrique Perdiguero Gil, Professor of History of Medicine, Department of Public Health, Sant Joan D'Alacant, Spain.

\section{REFERENCES}

1. Kaiser J. NIH funding. Success rates squeezed as budget growth slows. Science. 2005 Feb 18;307(5712):1023.

2. Schiermeier Q. Political deadlock delays promised German research cash. Nature. 2005 Feb 3;433(7025):448.

3. Why are French scientists striking? Lancet. 2004 Mar 20;363(9413):909.

4. Fischer A. French scientists take a stand. Science. 2004 Feb 13;303(5660):954.

5. Nelson L. Election promise gives hope to Spanish scientists. Nature. 2004 Apr 8;428(6983):592.

6. Vogel G. European research. A framework for change? Science. 2005 Apr 15;308(5720):342-4.

7. Burazeri G, Laaser U, Bjegovic V, Georgieva L; Consortium for Public Health Collaboration in South Eastern Europe. Regional collaboration in public health training and research among countries of South Eastern Europe. Eur J Public Health. 2005 Feb; 15(1):97-9.

8. Levett J, Kyriopoulos J. Public health in the Balkan region: one school's experience. Eur J Public Health. 2006 Jun;16(3):235-7. 
9. McKee M. The need for development assistance for health in the eastern European Region. Bull World Health Organ. 2005 Dec;83(12):883.

10. Jorgova-Makedonska JB. A view from Sofia. Circulation. 2006 Mar 28;113(12):f45-6.

11. McKee M, Balabanova D, Steriu A. A new year, a new era: Romania and Bulgaria join the European Union. Eur J Public Health. 2007 Apr;17(2):119-20.

12. Bulgaria and Romania join the European Union [editorial]. Lancet. 2007 Jan 6;369(9555):2.

13. Georgieva L, Powles J, Genchev G, Salchev P, Poptodorov G. Bulgarian population in transitional period. Croat Med J. 2002 Apr;43(2):240-4.

14. Aleksandrova S. The Bulgarian Health Care Reform and Health Act 2004. Med Law. 2007 Mar;26(1):1-14.

15. United States National Library of Medicine [homepage on the Internet]. About the National Library of Medicine [cited 2008 Mar 15]. Available from: http://www.nlm.nih.gov/about/index.html.

16. Plikus MV, Zhang Z, Chuong CM. PubFocus: semantic MEDLINE/ PubMed citations analytics through integration of controlled biomedical dictionaries and ranking algorithm. BMC Bioinformatics. 2006 Oct $2 ; 7: 424$.

17. Decision No 1786/2002/Ec of the European Parliament and of the council of 23 September 2002 adopting a programme of Community action in the field of public health (2003-2008). Off J Eur Communit. 2002 Oct 9;45(L271/1):1-11.

18. Gerlinger T, Schmucker R. Transnational migration of health professionals in the European Union. Cad Saude Publica. 2007;23 Suppl 2:S184-92.

19. Gregan J. Eastern European nurtures talent for the West. Nature. 2003 Feb 20;421(6925):786.

20. Kevelaitis E, Grabauskas V. Towards the impact factor. Medicina (Kaunas). 2007;43(2):91-5.

21. McKee M, Fister K. Post-communist transition and health in Europe. BMJ. 2004 Dec 11;329(7479):1355-6.

22. EurActiv [homepage on the Internet]. Health and Lifestyle. McKee M European Public Health Alliance. Health and the challenges of enlargement [cited 2007 Jun 23]. Available from: http://www.euractiv.com/en/ health/health-challenges-enlargement/article-117132.

23. EurActiv [homepage on the Internet]. Newley C, Nolte E, McKee M, Mosialos E. Avoidable mortality in the enlarged European Union [cited 2007 Jul 12]. Available from: http://www.euractiv.com/28/images/ISS\%20Avoid able\%20Mortality\%20final\%20\%20Nov\%2004 tcm28-132956.pdf.

24. Axmann A. Eastern Europe and Community of Independent States. Int Migr. 1998;36(4):587-607.
25. Kelly JA, Amirkhanian YA, Kabakchieva E, Csepe P, Seal DW, Antonova $\mathrm{R}$, et al. Gender roles and HIV sexual risk vulnerability of Roma (Gypsies) men and women in Bulgaria and Hungary: an ethnographic study. AIDS Care. 2004 Feb;16(2):231-45.

26. Kostova P, Zlatkov V, Danon S. Epidemiological prognosis of cervical cancer in Bulgaria for the period 1997-2010. J BUON. 2003 JanMar;8(1):49-53.

27. Quinn MJ, d'Onofrio A, Møller B, Black R, Martinez-Garcia C, Møller $\mathrm{H}$, et al. Cancer mortality trends in the EU and acceding countries up to 2015. Ann Oncol. 2003 Jul;14(7):1148-52.

28. Dokova KG, Stoeva KJ, Kirov PI, Feschieva NG, Petrova SP, Powles JW. Public understanding of the causes of high stroke risk in northeast Bulgaria. Eur J Public Health. 2005 Jun;15(3):313-6.

29. Balabanova D, Bobak M, McKee M. Patterns of smoking in Bulgaria. Tob Control. 1998;7(4):383-5.

30. Bray I, Brennan P, Boffetta P. Projections of alcohol- and tobacco-related cancer mortality in Central Europe. Int J Cancer. 2000 Jul 1;87(1):122-8

31. Matković T, Sucur Z, Zrinscak S. Inequality, poverty, and material deprivation in new and old members of the European Union. Croat Med J. 2007 Oct;48(5):636-52.

32. World Health Organization [homepage on the Internet]. Countries: Bulgaria [cited 2007 Mar 14]. Available from: http://www.who.int/countries/bgr/en/.

33. World Health Organization [homepage on the Internet]. Countries: United States of America [cited 2007 Mar 14]. Available from: http://www.who int/countries/usa/en/.

34. Schreiber K, Kindler CH. Bibliometric analysis of anaesthetic molecular biology research in Germany, Austria and Switzerland. Anaesthesist. 2005 Nov;54(11):1094-9. (In German.)

35. Radut DS, Alvarez-Dardet C, Ruiz MT. Medical scientific Romania in the European context. Oftalmologia. 2006;50(2):10-7. (In Romanian.)

36. Miguel-Dasit A, Martí-Bonmatí L, Aleixandre R, Sanfeliu P, Valderrama JC. Spanish production of research articles on diagnostic imaging in cardiology and radiology (1994-1998). Rev Esp Cardiol. 2004 Sep;57(9):806-14. (In Spanish.)

37. Camí J, Suñén-Piñol E, Méndez-Vásquez R. Bibliometric map of Spain 1994-2002: biomedicine and health sciences. Med Clin (Barc). 2005 Jan 29;124(3):93-101. Erratum in: Med Clin (Barc). 2005 Mar 26;124(11):414. (In Spanish.)

Received May 5, 2008 Accepted August 14, 2008 